\title{
Association between inflammatory bowel disease and prostate cancer: A large-scale, prospective, population-based study
}

Travis J. Meyers, PhD ${ }^{1, *}$, Adam B. Weiner, MD",*, Rebecca E. Graff, PhD ${ }^{1}$, Anuj S. Desai ${ }^{2}$, Lauren Folgosa Cooley, MD PhD², William J. Catalona, $\mathrm{MD}^{2}$, Stephen B. Hanauer, MD ${ }^{3}$, Jennifer D. Wu, PhD' ${ }^{2}$, Edward M. Schaeffer, MD PhD ${ }^{2}$, Sarki A. Abdulkadir, MD $\mathrm{PhD}^{2}$, Shilajit D. Kundu, $\mathrm{MD}^{2, \dagger}$, John S. Witte, $\mathrm{PhD}^{1,4, \dagger}$

${ }^{*}$ Co-first authors; ${ }^{\dagger}$ Co-senior authors

\section{Affiliations:}

1. Department of Epidemiology and Biostatistics, University of California, San Francisco (UCSF), San Francisco, CA

2. Department of Urology, Northwestern University Feinberg School of Medicine, Chicago, IL

3. Department of Medicine, Division of Gastroenterology and Hepatology, Northwestern University Feinberg School of Medicine, Chicago, IL

4. Department of Urology, UCSF

\section{Corresponding Author Information:}

John S. Witte, PhD

University of California, San Francisco

$14503^{\text {rd }}$ Street, Room 388

San Francisco, CA 94158

Phone: 415-502-6882

E-mail: JWitte@ucsf.edu

Shilajit D. Kundu, MD

Northwestern Medicine

675 N. St. Clair Street

Galter 20-236

Chicago, IL 60611

Phone: 312-695-6125

Email: s-kundu@northwestern.edu

Acknowledgements: This research was funded by the following $\mathrm{NIH}$ grants: $\mathrm{NCl}$ R25CA112355, R01CA201358, and NIA T32AG049663. This research was conducted with approved access to UK Biobank data under application number 14105.

\section{Abstract word count: 282; Text word count: 2,494; Total: 2,776}

Keywords: cohort study; epidemiology; inflammatory bowel disease; prostate cancer; UK Biobank; ulcerative colitis 


\section{Abstract}

Background: Inflammatory bowel disease (IBD) is an established risk factor for colorectal cancer. Recent reports suggesting IBD is also a risk factor for prostate cancer $(P C)$ require further investigation.

Objective: To test the association between IBD with incident PC.

Design, setting, and participants: We studied 218,084 men in the populationbased UK Biobank cohort, aged 40-69 at study entry between 2006 and 2010, with follow-up through mid-2015.

Outcome measurements and statistical analysis: We assessed the association between IBD and subsequent PC using multivariable Cox regression analyses, adjusting for age at assessment, ethnic group, UK region, smoking status, alcohol drinking frequency, body mass index, Townsend Deprivation Index, family history of prostate cancer, and previous prostate-specific antigen testing.

Results and limitations: Mean age at study entry was 56 years, 94\% of the men were white, and $1.1 \%(n=2,311)$ had a diagnosis of IBD. After a median follow-up of 78 months, men with IBD had an increased risk of PC (adjusted hazards ratio [aHR] = $1.31,95 \%$ Confidence interval $[\mathrm{Cl}]=1.03-1.67, \mathrm{p}=0.029)$. Separately analyzing the IBD subtypes of ulcerative colitis (UC) and Crohn's disease (CD), the association with $\mathrm{PC}$ was only among men with the former $(\mathrm{UC}$; $\mathrm{aHR}=1.47,95 \% \mathrm{Cl}=1.11-1.95$, $\mathrm{p}=0.0070)$, and not the latter $(C D ;$ aHR $1.06,95 \% \mathrm{Cl}=0.63-1.80, \mathrm{p}=0.82)$. Results are limited by lack of data on frequency of health care interactions.

Conclusions: In a large-scale, prospective cohort study, we detected an association between IBD, and UC specifically, with incident PC diagnosis. 
medRxiv preprint doi: https://doi.org/10.1101/2020.01.16.20017707; this version posted January 18, 2020. The copyright holder for this preprint (which was not certified by peer review) is the author/funder, who has granted medRxiv a license to display the preprint in perpetuity. It is made available under a CC-BY-NC-ND 4.0 International license.

25 with inflammatory bowel disease may be at a higher risk of prostate cancer than the

26 general population.

27

28

29

30

31

32

33

34

35

36

37

38

39

40

41

42

43

44

45

46 


\section{Introduction}

$48 \quad$ Prostate cancer (PC) is the second most common non-cutaneous malignancy in

49 men globally, accounting for 1.3 million new cases and over 350,00 deaths in 2018

50 globally ${ }^{1}$. Screening for PC may help reduce PC mortality at the potential cost of

51 overdiagnosis leading to unnecessary exposure to treatment related morbidities ${ }^{2,3}$.

52 Guidelines in both the United States and Europe acknowledge the benefits of identifying

53 risk factors for PC to better counsel men on the use of prostate-specific antigen (PSA)-

54 based screening ${ }^{4,5}$.

$55 \quad$ While inflammatory bowel disease (IBD) is an established risk factor for

56 colorectal cancer ${ }^{6}$, associations between IBD with prostate cancer have been reported

57 for some studies ${ }^{7-13}$ but not others ${ }^{14-16}$. We thus conducted a prospective study of men

58 from the large-scale, population-based UK Biobank cohort ${ }^{17}$ to test this association.

59 Men in the UK historically have low rates of PC screening (3-11\% after age 50 years) ${ }^{18}$

60 and PC screening is not currently recommended by the UK National Screening

61 Committee ${ }^{19}$. We hypothesized that men in the UK Biobank with a diagnosis of IBD

62 would experience a higher incidence of subsequent PC diagnosis.

63

64

65

66

67

68

69 


\section{Patients and Methods}

\section{Study population}

73 The UK Biobank is a prospective, population-based study established to

74 investigate genetic and non-genetic risk factors for disease in individuals of middle and

75 advanced age ${ }^{17}$. The details of study design and data collection have previously been

76 described and the complete protocol can be found online ${ }^{17,20}$. In summary, 500,796

77 participants aged 40-69 years registered within the National Health Service (NHS) and

78 living within $40 \mathrm{~km}$ of one of 22 assessment centers across England, Scotland, and

79 Wales were recruited between 2006 and 2010. Each participant provided written

80 informed consent and the UK Biobank's study protocol was approved by the UK North

81 West Multicenter Research Ethics Committee. Baseline assessments at entry into the

82 cohort were made for each participant in 90-minute appointments which included

83 questionnaires, sample collections, and health care physical exams and interviews.

84 Participants are linked to the NHS Central register to capture IBD status, cancer

85 diagnoses, and deaths.

$86 \quad$ Since the present outcome of interest was prostate cancer, the analytical cohort

87 was limited to self-reported male participants $(n=228,284)$. We excluded men if at

88 baseline assessment they had: 1) prior history of a malignant cancer (any site), or

89 timing of malignant cancer diagnosis relative to baseline could not be determined

$90(n=9,902,4.3 \%) ; 2)$ surgical removal of the prostate $(n=64,<0.01 \%$; NHS procedure

91 codes: OPCS version 3- 630-635; OPCS version 4-M61); 3) earlier recorded death date

$92(n=1,<0.01 \%)$. We also excluded $233(<0.01 \%)$ individuals whose genetically inferred

93 sex was female. The remaining 218,084 men comprised the study population. 


\section{Exposure}

The exposure of interest was a history of IBD (ulcerative colitis [UC] or Crohn's

97 disease [CD]) at the time of baseline assessment. IBD history was considered present if

98 the participant had either a relevant inpatient ICD code or self-reported illness. ICD10

99 codes for $\mathrm{UC}$ and $\mathrm{CD}$ were $\mathrm{K} 51$ and $\mathrm{K} 50$, respectively. ICD9 codes for $\mathrm{UC}$ and CD were

100556 and 555. Self-reported IBD and the approximate date that a doctor first diagnosed

101 IBD were collected during the baseline assessment interview. If a participant had

102 recorded diagnoses for both $U C$ and $C D$, then they were still included in the analysis of

103 overall IBD but not in the subtype analyses.

104

Outcome

106 The outcome of interest was first diagnosis of malignant PC following baseline

107 assessment. Prostate cancer case status was determined using ICD codes (ICD-9: 185,

108 ICD-10: C61). Follow-up data for the UK Biobank cohort was available through the

109 middle of 2015.

110

111 Covariates

112 Covariates included in multivariable analyses included age at baseline

113 assessment (continuous), self-reported ethnicity (White, Mixed, South Asian, Chinese,

114 Black, or other), region of assessment center (10 cancer registry regions), Townsend

115 Deprivation Index (TDI; quintiles), smoking status (never, former, or current), alcohol

116 drinking frequency (never, special occasions only, 1-3 times per month, 1-2 times per 
117 week, 3-4 times per week, daily/almost daily), body mass index (BMl; quintiles), family

118 history of PC in biological relatives (yes, no), and history of PSA testing (yes, no). All

119 categorical variables included a category for missingness.

Statistical analyses

Person-years were calculated from the date of baseline assessment until

123 diagnosis of PC, diagnosis of a different malignant cancer, prostatectomy, death, or end

124 of follow-up, whichever came first. The non-PC endpoints were considered censoring

125 events. If PC diagnosis followed any of the other censoring events within three months,

126 then PC was used as the endpoint and the time to PC was included as the follow-up

127 time. The rationale was that the censoring event may have been correlated with PC 128 diagnosis.

129 Incidence rates for PC were calculated for each baseline group (no IBD, any IBD,

$130 \mathrm{UC}$, or $\mathrm{CD}$ ) from the number of incident PC cases divided by the person-years of follow-

131 up in each group. Kaplan-Meier curves were fit comparing survival for men with IBD

132 (any IBD, UC, or CD) at baseline to those without IBD at baseline. The difference in

133 survival by IBD status was compared by the univariate log-rank test.

$134 \quad$ Adjusted hazard ratios (aHRs) and 95\% confidence intervals (Cls) for the

135 association between IBD and PC were calculated using Cox proportional hazards

136 models adjusting for all aforementioned covariates. This analysis was the basis for

137 testing our main hypothesis. We further investigated whether the potential association

138 between IBD and PC varied by: 1) IBD subtype; 2) duration of living with IBD (using 20

139 years from IBD diagnosis until baseline assessment in UK Biobank as the cut point); 
140 and 3 ) age at assessment (using 60 years as the cut point). For analysis 1 and 2, we

141 performed the same regression as the primary analysis except IBD status was stratified

142 as $\mathrm{UC}, \mathrm{CD}$, or no IBD and IBD $>20$ year, IBD $\leq 20$ years, or no IBD, respectively. For

143 analysis 3 , we created a new model which included age categorized as $\leq 60$ or $>60$

144 years as opposed to continuous and an interaction term between this new age variable

145 and IBD status (IBD or no IBD).

146 To determine the appropriateness of our Cox models, we tested the underlying

147 assumption that the relative incidence of PC between men with and without IBD was

148 constant over time (proportional hazards). Specifically, the correlation between scaled

149 Schoenfeld residuals with follow-up time was tested, based on the univariable Cox

150 model with IBD status as the regressor. All statistical analyses were conducted using $\mathrm{R}$

151 statistical software, version 3.6.0: Kaplan-Meier plots were generated by the 'survminer'

152 package; Cox models were conducted using the 'survival' package.

153

154

155

156

157

158

159

160

161

162

163 


\section{Results}

165 Study participants

At baseline assessment, there were 2,311 men with a history of IBD and 215,773

167 men without a history of IBD (Table 1). Compared to men without IBD, men with IBD

168 were on average one year older ( 57.3 vs. $56.5 ; p<0.05)$, were more likely to be White

169 (95.3\% vs. 93.8\%; $p<0.05)$, were more likely to be former smokers $(49.5 \%$ vs. $37.7 \%)$

170 than current smokers (8.9\% vs. $12.6 \%$ ), and had a lower average BMI (27.5 vs. $27.8 ; p$

$171<0.05)$. All participants were similar with respect to average TDI (No IBD: -1.25; IBD: -

172 1.19; negative values reflect relative affluence), family history of PC (both $7.7 \%$ ), and

173 history of PSA testing (No IBD: 27.6\%; IBD: 26.9\%). Of those with IBD, 1,488

174 exclusively had UC and 643 exclusively had CD. Compared to men with $C D$, men with

175 UC were on average one year older ( 57.7 vs. $56.4 ; p<0.05)$, had a lower TDI (-1.33 vs.

$176-0.88 ; p<0.05)$, were more likely to be former smokers $(51.2 \%$ vs. $47.6 \%)$ than current

177 smokers (6.7\% vs. $13.7 \%)$, and had a higher average BMI (27.7 vs. $27.1, p<0.05)$.

179 Prostate cancer incidence based on inflammatory bowel disease status

After a median follow-up of 78 months (over 1.3 million person-years for men

181 without IBD and 14,379 years for men with IBD), there were 4,681 new cases of PC in

182 men without IBD and 66 in men with IBD (Table 2). Men with IBD demonstrated a

183 shorter time to developing PC (Log-rank, $p=0.018$; Figure 1). The assumption of

184 proportional hazards was satisfied for each univariate model for baseline status of any

185 IBD, UC, or CD. The incidence rates for PC (cases per 100,000 person-years) were 343

186 for non-IBD and 459 for men with IBD. After adjusting for covariates, IBD was 
187 associated with an increased hazard of $\mathrm{PC}(\mathrm{aHR}=1.31,95 \% \mathrm{Cl}=1.03-1.67, \mathrm{p}=$

$188 \quad 0.029$; Table 2). Further adjusting for history of partial or complete colectomy did not

189 meaningfully change the HR so it was not included in the final models. In addition, we

190 observed a trend for increasing HR across years since IBD diagnosis $(<=20$ years, aHR

$191=1.22 ;>20$ years, aHR $=1.49 ; p$-trend $=0.018 ;$ Table 3 ). We did not detect interaction

192 by age at study assessment $(p=0.92)$.

193

194 Prostate cancer incidence based on inflammatory bowel disease subtype

195 The person-years for men with exclusively one IBD subtype were comprised of

1969,201 for men with UC and 4,021 for men with CD (Table 2). A total of 49 men with UC

197 and 14 men with CD developed PC. While men with UC developed PC more rapidly

198 than men without IBD (Log-rank $p=0.0023,533$ cases per 100,000 person-years), those

199 with CD did not (Log-rank $p=0.95 ; 348$ cases per 100,00 person-years; Figure 2). The

200 same associations were noted on adjusted analysis (UC: aHR $=1.47,95 \% \mathrm{Cl}=1.11$ -

201 1.95, $p=0.0070 ; \mathrm{CD}: \mathrm{aHR}=1.06,95 \% \mathrm{Cl}=0.63-1.80, \mathrm{p}=0.82 ;$ Table 2). For the UC

202 subtype, increasing HR was also noted across years since diagnosis $(<=20$ years, aHR

$203=1.29 ;>20$ years, aHR = 1.87; $p$-trend $=0.0022 ;$ Table 3 ).

204

205

206

207

208

209 


\section{Discussion}

$211 \quad$ IBD is a chronic inflammatory condition with a growing prevalence, affecting at

212 least $0.3 \%$ of individuals in developed countries $^{21}$. In a large, prospective cohort of men

213 in the UK, where PC screening is low ( $27 \%$ in our cohort), we found a positive

214 association between IBD and PC. This association was driven by an approximate $50 \%$

215 increase in PC risk among men with UC. These findings suggest that even outside the

216 setting of routine PC screening, men with IBD are at an increased risk of PC.

217 The limited research into IBD and PC has demonstrated conflicting results. In a

218 recent, large, retrospective study at a single medical center, men with IBD undergoing

219 PC screening had a greater than four-fold increase in incident PC and high-grade PC

220 compared to men without IBD ${ }^{9}$. In a case-control study within a shared, equal-access

221 healthcare system, men with IBD had a $70 \%$ increased risk of $\mathrm{PC}^{7}$. In contrast, other

222 studies and a meta-analysis found no clear association between IBD and PC ${ }^{14-16}$. Three

223 studies reported the association for UC but not $C D^{8,12,13}$, as we observed in the present

224 study. A pair of studies observed the association for both $C D^{10}$ and $U C^{11}$, although the

225 associations were attenuated when cancers diagnosed within the first year after IBD

226 diagnosis were excluded. Much of this prior research included men younger than 50

227 and thus at low risk of $P C^{8,12,13,15,16}$, which may explain why two of these studies

228 reported no IBD-PC association ${ }^{15,16}$. In contrast, the UK Biobank was designed to study

229 age-related diseases ${ }^{20}$.

230 Several mechanisms may explain the potential relationship between IBD and PC.

231 Chronic inflammation is a risk factor for cancer development in various solid tumors and

232 may contribute to prostate tumorigenesis by inducing DNA damage and promoting 
medRxiv preprint doi: https://doi.org/10.1101/2020.01.16.20017707; this version posted January 18, 2020. The copyright holder for this preprint (which was not certified by peer review) is the author/funder, who has granted medRxiv a license to display the preprint in perpetuity. It is made available under a CC-BY-NC-ND 4.0 International license .

233 carcinogenic epigenetic alterations ${ }^{22}$. Chronic inflammation may play a role in the well-

234 established association between IBD and colorectal cancer ${ }^{6}$, though it is unknown

235 whether chronic gut inflammation leads to changes in the prostatic inflammatory milieu.

236 Transmission of gut inflammation to the prostate may occur via local inflammation in the

237 rectum, which is nearly universal in UC and less frequently observed in CD. These IBD

238 subtypes have distinct clinical and pathologic features ${ }^{23}$. While local inflammation may

239 help to explain our observation and prior reports that UC, not CD, is associated with PC,

240 further research is warranted, in particular the documentation of adjacent rectal

241 inflammation in patients with UC vs. CD. An alternative factor may be elevated serum

242 (systemic) inflammatory markers, which are known to occur in $\mathrm{IBD}^{24}$ and may play a

243 role in PC development and progression ${ }^{22}$. In contrast, immunomodulatory medications

244 commonly used in IBD have been associated with other extra-intestinal

245 malignancies ${ }^{14,25}$, suggesting immunosuppression may also be responsible for prostate

246 tumorigenesis or progression. Lastly, shared underlying genetics may explain the IBD-

247 PC association, although preliminary evidence across common gene variants has not

248 detected genetic correlations for either UC or CD with $\mathrm{PC}^{26}$.

249 The potential link between IBD and PC has important implications for screening 250 and detection of PC. While recommendations are controversial, some guideline panels

251 have supported more aggressive screening in high risk populations ${ }^{4,5}$. Older age,

252 African-ancestry, and family history of PC have been consistently identified as risk

253 factors for PC development ${ }^{27}$. Our study suggests that IBD may be an independent risk

254 factor for PC, but future study is needed to determine how to appropriately apply this

255 finding to patient screening practices. 
There are several important limitations of our study. First, we were unable to

257 account for frequency of healthcare encounters in our analysis of incident PC. Men with

258 IBD have more frequent healthcare encounters ${ }^{28}$, are more likely to undergo rectal

259 examinations, and may be subject to opportunistic screening. Our analysis was

260 adjusted for whether the participant had a PSA test prior to entry into the UK Biobank,

261 however, we were unable to account for number of prior PSA tests or digital rectal

262 examinations. Nevertheless, in a sensitivity analysis, we observed that in men with no

263 history of a PSA test, the hazard ratios were greater by $10 \%$ and $12 \%$ for IBD and UC,

264 respectively compared to the models including all men and with PSA test as a covariate.

265 Second, the release of the UK Biobank data at the time we performed the analysis did

266 not provide information regarding cancer grade or stage; thus, we were unable to

267 differentiate between low-risk and clinically significant cancer. Third, given the relatively

268 few cancer diagnoses overall, we report incidence of PC diagnosis, but not morbidity or

269 mortality related to diagnosis and treatment. Lastly, important characteristics of the UK

270 Biobank limit the generalizability of these results. Participants in the study, compared to

271 nonparticipants in the UK, are noted to be older, of higher socioeconomic status,

272 predominantly Caucasian, and generally healthy-all of which have important relevance

273 in PC screening and diagnosis. In addition, participants of the UK Biobank have lower

274 all-cause mortality and total cancer incidence compared to nonparticipants which may

275 suggest that our results under-estimate the burden of PC in men with IBD in the UK ${ }^{29}$. 
medRxiv preprint doi: https://doi.org/10.1101/2020.01.16.20017707; this version posted January 18, 2020. The copyright holder for this preprint

(which was not certified by peer review) is the author/funder, who has granted medRxiv a license to display the preprint in perpetuity.

It is made available under a CC-BY-NC-ND 4.0 International license.

\section{Conclusions}

280 In this large-scale cohort study outside the setting of widespread PC screening,

281 men with IBD had an increased risk of incident PC compared to men without IBD.

282 Future work is needed to validate this association accounting for PC screening and

283 other covariates, and determine potential mechanisms of prostate tumorigenesis in men

284 with IBD. Ultimately, this work could provide an avenue for incorporating information

285 about IBD into screening decisions for PC. 
medRxiv preprint doi: https://doi.org/10.1101/2020.01.16.20017707; this version posted January 18, 2020. The copyright holder for this preprint

(which was not certified by peer review) is the author/funder, who has granted medRxiv a license to display the preprint in perpetuity.

It is made available under a CC-BY-NC-ND 4.0 International license .

\section{References}

1. Bray F, Ferlay J, Soerjomataram I, Siegel RL, Torre LA, Jemal A. Global cancer statistics 2018: GLOBOCAN estimates of incidence and mortality worldwide for 36 cancers in 185 countries. CA Cancer J Clin. 2018;68(6):394-424. doi:10.3322/caac.21492

2. Hugosson J, Roobol MJ, Månsson M, et al. A 16-yr Follow-up of the European Randomized study of Screening for Prostate Cancer. Eur Urol. 2019;76(1):43-51. doi:10.1016/j.eururo.2019.02.009

3. Loeb S, Bjurlin MA, Nicholson J, et al. Overdiagnosis and overtreatment of prostate cancer. Eur Urol. 2014;65(6):1046-1055. doi:10.1016/j.eururo.2013.12.062

4. US Preventive Services Task Force, Grossman DC, Curry SJ, et al. Screening for Prostate Cancer: US Preventive Services Task Force Recommendation Statement. JAMA. 2018;319(18):1901-1913. doi:10.1001/jama.2018.3710

5. Gandaglia G, Albers P, Abrahamsson P-A, et al. Structured Population-based Prostate-specific Antigen Screening for Prostate Cancer: The European Association of Urology Position in 2019. Eur Urol. 2019;76(2):142-150. doi:10.1016/j.eururo.2019.04.033

6. Dulai PS, Sandborn WJ, Gupta S. Colorectal Cancer and Dysplasia in Inflammatory Bowel Disease: A Review of Disease Epidemiology, Pathophysiology, and Management. Cancer Prev Res (Phila Pa). September 2016. doi:10.1158/1940-6207.CAPR-16-0124

7. Mosher CA, Brown GR, Weideman RA, et al. Incidence of Colorectal Cancer and Extracolonic Cancers in Veteran Patients With Inflammatory Bowel Disease. Inflamm Bowel Dis. 2018;24(3):617-623. doi:10.1093/ibd/izx046

8. Kappelman MD, Farkas DK, Long MD, et al. Risk of Cancer in Patients with Inflammatory Bowel Diseases: a Nationwide Population-Based Cohort Study with 30 Years of Follow Up. Clin Gastroenterol Hepatol Off Clin Pract J Am Gastroenterol Assoc. 2014;12(2):265-73.e1. doi:10.1016/j.cgh.2013.03.034

9. Burns JA, Weiner AB, Catalona WJ, et al. Inflammatory Bowel Disease and the Risk of Prostate Cancer. Eur Urol. 2019;75(5):846-852.

doi:10.1016/j.eururo.2018.11.039

10. Hemminki K, Li X, Sundquist J, Sundquist K. Cancer risks in Crohn disease patients. Ann Oncol Off J Eur Soc Med Oncol. 2009;20(3):574-580. doi:10.1093/annonc/mdn595

11. Hemminki K, Li X, Sundquist J, Sundquist K. Cancer risks in ulcerative colitis patients. Int J Cancer. 2008;123(6):1417-1421. doi:10.1002/ijc.23666 
medRxiv preprint doi: https://doi.org/10.1101/2020.01.16.20017707; this version posted January 18, 2020. The copyright holder for this preprint

(which was not certified by peer review) is the author/funder, who has granted medRxiv a license to display the preprint in perpetuity. It is made available under a CC-BY-NC-ND 4.0 International license .

12. Jess T, Horváth-Puhó E, Fallingborg J, Rasmussen HH, Jacobsen BA. Cancer risk in inflammatory bowel disease according to patient phenotype and treatment: a Danish population-based cohort study. Am J Gastroenterol. 2013;108(12):18691876. doi:10.1038/ajg.2013.249

13. Jung YS, Han M, Park S, Kim WH, Cheon JH. Cancer Risk in the Early Stages of Inflammatory Bowel Disease in Korean Patients: A Nationwide Population-based Study. J Crohns Colitis. 2017;11(8):954-962. doi:10.1093/ecco-jcc/jjx040

14. Pedersen N, Duricova D, Elkjaer M, Gamborg M, Munkholm P, Jess T. Risk of extra-intestinal cancer in inflammatory bowel disease: meta-analysis of populationbased cohort studies. Am J Gastroenterol. 2010;105(7):1480-1487. doi:10.1038/ajg.2009.760

15. Wilson JC, Furlano RI, Jick SS, Meier CR. A population-based study examining the risk of malignancy in patients diagnosed with inflammatory bowel disease. $J$ Gastroenterol. 2016;51(11):1050-1062. doi:10.1007/s00535-016-1199-8

16. van den Heuvel TRA, Wintjens DSJ, Jeuring SFG, et al. Inflammatory bowel disease, cancer and medication: Cancer risk in the Dutch population-based IBDSL cohort. Int J Cancer. 2016;139(6):1270-1280. doi:10.1002/ijc.30183

17. Sudlow C, Gallacher J, Allen N, et al. UK biobank: an open access resource for identifying the causes of a wide range of complex diseases of middle and old age. PLoS Med. 2015;12(3):e1001779. doi:10.1371/journal.pmed.1001779

18. Williams N, Hughes LJ, Turner EL, et al. Prostate-specific antigen testing rates remain low in UK general practice: a cross-sectional study in six English cities. BJU Int. 2011;108(9):1402-1408. doi:10.1111/j.1464-410X.2011.10163.x

19. Prostate Cancer. https://legacyscreening.phe.org.uk/prostatecancer. Accessed December 23, 2019.

20. Key documents | UK Biobank. https://www.ukbiobank.ac.uk/key-documents/. Accessed November 19, 2019.

21. Ng SC, Shi HY, Hamidi N, et al. Worldwide incidence and prevalence of inflammatory bowel disease in the 21st century: a systematic review of populationbased studies. Lancet Lond Engl. 2018;390(10114):2769-2778. doi:10.1016/S0140-6736(17)32448-0

22. Sfanos KS, Yegnasubramanian S, Nelson WG, De Marzo AM. The inflammatory microenvironment and microbiome in prostate cancer development. Nat Rev Urol. 2018;15(1):11-24. doi:10.1038/nrurol.2017.167

23. Souza HSP de, Fiocchi C. Immunopathogenesis of IBD: current state of the art. Nat Rev Gastroenterol Hepatol. 2016;13(1):13-27. doi:10.1038/nrgastro.2015.186 
24. Vrakas S, Mountzouris KC, Michalopoulos G, et al. Intestinal Bacteria Composition and Translocation of Bacteria in Inflammatory Bowel Disease. PloS One. 2017;12(1):e0170034. doi:10.1371/journal.pone.0170034

25. Biancone L, Onali S, Petruzziello C, Calabrese E, Pallone F. Cancer and immunomodulators in inflammatory bowel diseases. Inflamm Bowel Dis. 2015;21(3):674-698. doi:10.1097/MIB.0000000000000243

26. Lindström S, Finucane $\mathrm{H}$, Bulik-Sullivan $\mathrm{B}$, et al. Quantifying the genetic correlation between multiple cancer types. Cancer Epidemiol Biomark Prev Publ Am Assoc Cancer Res Cosponsored Am Soc Prev Oncol. 2017;26(9):1427-1435. doi:10.1158/1055-9965.EPI-17-0211

27. Pernar CH, Ebot EM, Wilson KM, Mucci LA. The Epidemiology of Prostate Cancer. Cold Spring Harb Perspect Med. 2018;8(12):a030361.

doi:10.1101/cshperspect.a030361

28. Park KT, Ehrlich OG, Allen JI, et al. The Cost of Inflammatory Bowel Disease: An Initiative From the Crohn's \& Colitis Foundation. Inflamm Bowel Dis. May 2019. doi:10.1093/ibd/izz104

29. Fry A, Littlejohns TJ, Sudlow C, et al. Comparison of Sociodemographic and Health-Related Characteristics of UK Biobank Participants With Those of the General Population. Am J Epidemiol. 2017;186(9):1026-1034.

doi:10.1093/aje/kwx246 
Tables and Figures

Table 1. Baseline characteristics of male UK Biobank participants by IBD status at baseline assessment

\begin{tabular}{|c|c|c|c|c|}
\hline Characteristic & No IBD $(n=215,773)$ & IBD $(n=2,311)$ & CD $(n=643)$ & UC $(n=1,488)$ \\
\hline Age at assessment, mean (SD) & $56.5(8.2)$ & $57.3(8.0)^{*}$ & $56.4(8.1)$ & $57.7(7.9)^{*}, \dagger$ \\
\hline White, n (\%) & $202,433(93.8)$ & $2,203(95.3)^{*}$ & $621(96.6)$ & $1,410(94.8)^{*}$ \\
\hline Townsend Deprivation Index, mean (SD) & $-1.25(3.2)$ & $-1.19(3.2)$ & $-0.88(3.4)^{\star}$ & $-1.33(3.1) \dagger$ \\
\hline Region of assessment center, $\mathrm{n}(\%)$ & & * & * & * \\
\hline Southern England & $64,969(30.1)$ & $644(27.9)$ & $186(28.9)$ & $404(27.2)$ \\
\hline English Midlands & $35,126(16.3)$ & $410(17.7)$ & $113(17.6)$ & $278(18.7)$ \\
\hline Northern England & $91,886(42.6)$ & $951(41.2)$ & $249(38.7)$ & $632(42.5)$ \\
\hline Wales & $8,873(4.1)$ & $106(4.6)$ & $38(5.9)$ & $59(4.0)$ \\
\hline Scotland & $14,919(6.9)$ & $200(8.7)$ & $57(8.9)$ & $115(7.7)$ \\
\hline Smoking Status, n (\%) & & * & * & ${ }^{*} \dagger$ \\
\hline Never & $105,751(49.0)$ & $956(41.4)$ & $247(38.4)$ & $622(41.8)$ \\
\hline Former & $81,451(37.7)$ & $1,143(49.5)$ & $306(47.6)$ & $762(51.2)$ \\
\hline Current & $27,220(12.6)$ & $205(8.9)$ & $88(13.7)$ & $99(6.7)$ \\
\hline Alcohol drinking frequency, $\mathrm{n}(\%)$ & & * & * & ${ }^{*} \dagger$ \\
\hline Never & $13,568(6.3)$ & $190(8.2)$ & $57(8.9)$ & $116(7.8)$ \\
\hline Special occasions/1-3 times per month & $34,899(16.2)$ & $452(19.6)$ & $146(22.7)$ & $274(18.4)$ \\
\hline 1-2 times per week/3-4 times per week & $112,060(51.9)$ & $1,138(49.2)$ & $303(47.1)$ & $737(49.5)$ \\
\hline Daily/almost daily & $54,513(25.3)$ & $526(22.8)$ & $135(21.0)$ & $358(24.1)$ \\
\hline Body mass index, mean (SD) & $27.8(4.3)$ & $27.5(4.3)^{\star}$ & $27.1(4.3)^{*}$ & $27.7(4.2) \dagger$ \\
\hline Family history of prostate cancer, $\mathrm{n}(\%)$ & $16,526(7.7)$ & $179(7.7)$ & $50(7.8)$ & $111(7.5)$ \\
\hline Ever had a PSA test, $\mathrm{n}(\%)$ & $59,585(27.6)$ & $622(26.9)^{*}$ & $171(26.6)^{*}$ & $409(27.5)^{*}$ \\
\hline
\end{tabular}

Difference of means tested by t-tests; categorical variables tested by chi-square tests; alcohol drinking frequency tested by chi-square trend test

${ }^{*}$ P-value compared to No IBD $<0.05$

$\dagger$ P-value compared to $C D<0.05$

Abbreviations: IBD = Inflammatory bowel disease; $\mathrm{SD}$ = standard deviation; $\mathrm{CD}=$ Crohn's disease; $\mathrm{UC}=$ 
Ulcerative colitis

Percentages do not sum to $100 \%$ due to missing data 
Figure 1. Kaplan-Meier analysis of prostate cancer incidence by inflammatory bowel disease status

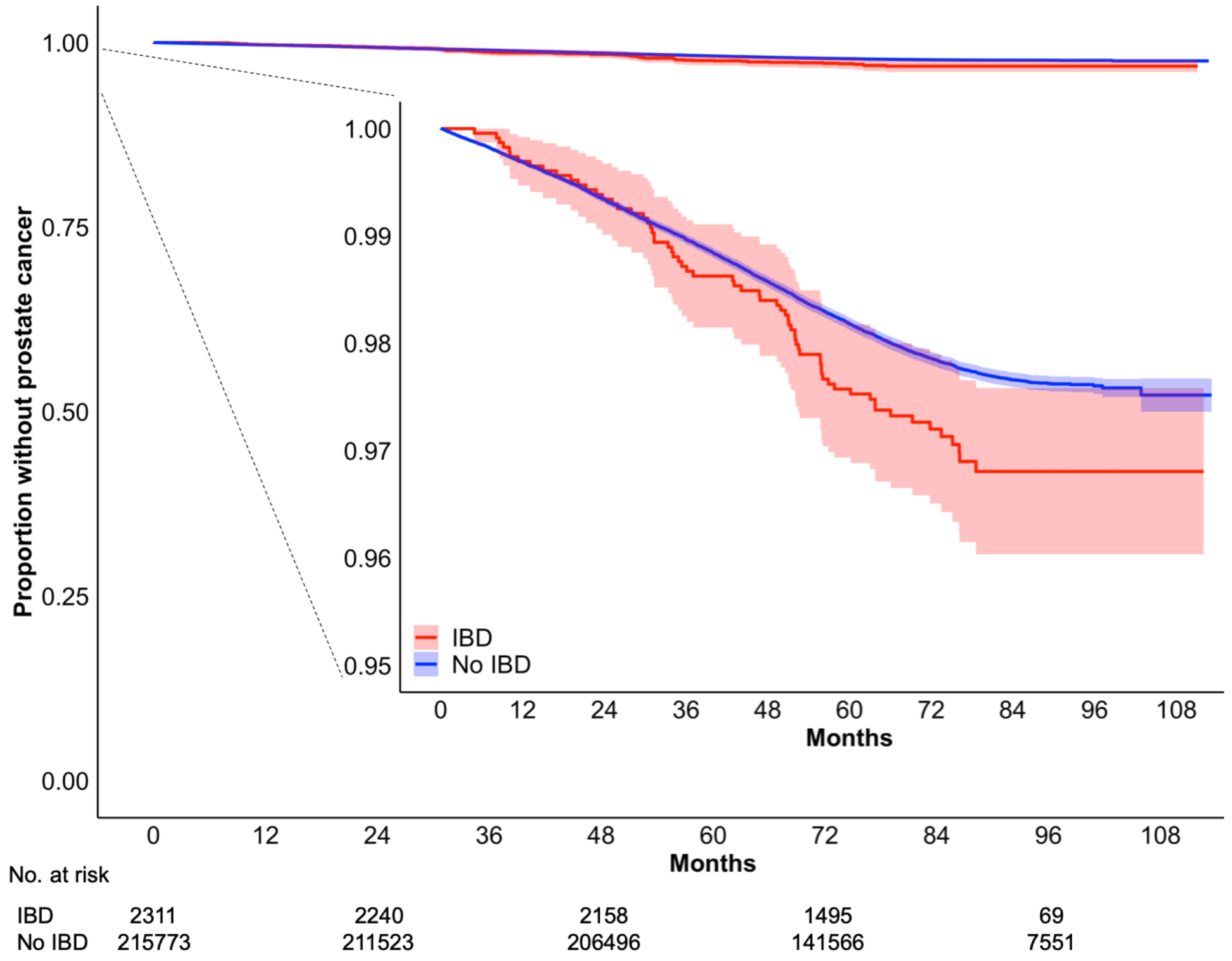


Shading represents $95 \%$ confidence intervals. Log-rank comparing IBD to no IBD $p=0.018$.

Abbreviations: IBD = Inflammatory bowel disease 
Figure 2. Kaplan-Meier analysis of prostate cancer incidence by inflammatory bowel disease subtype

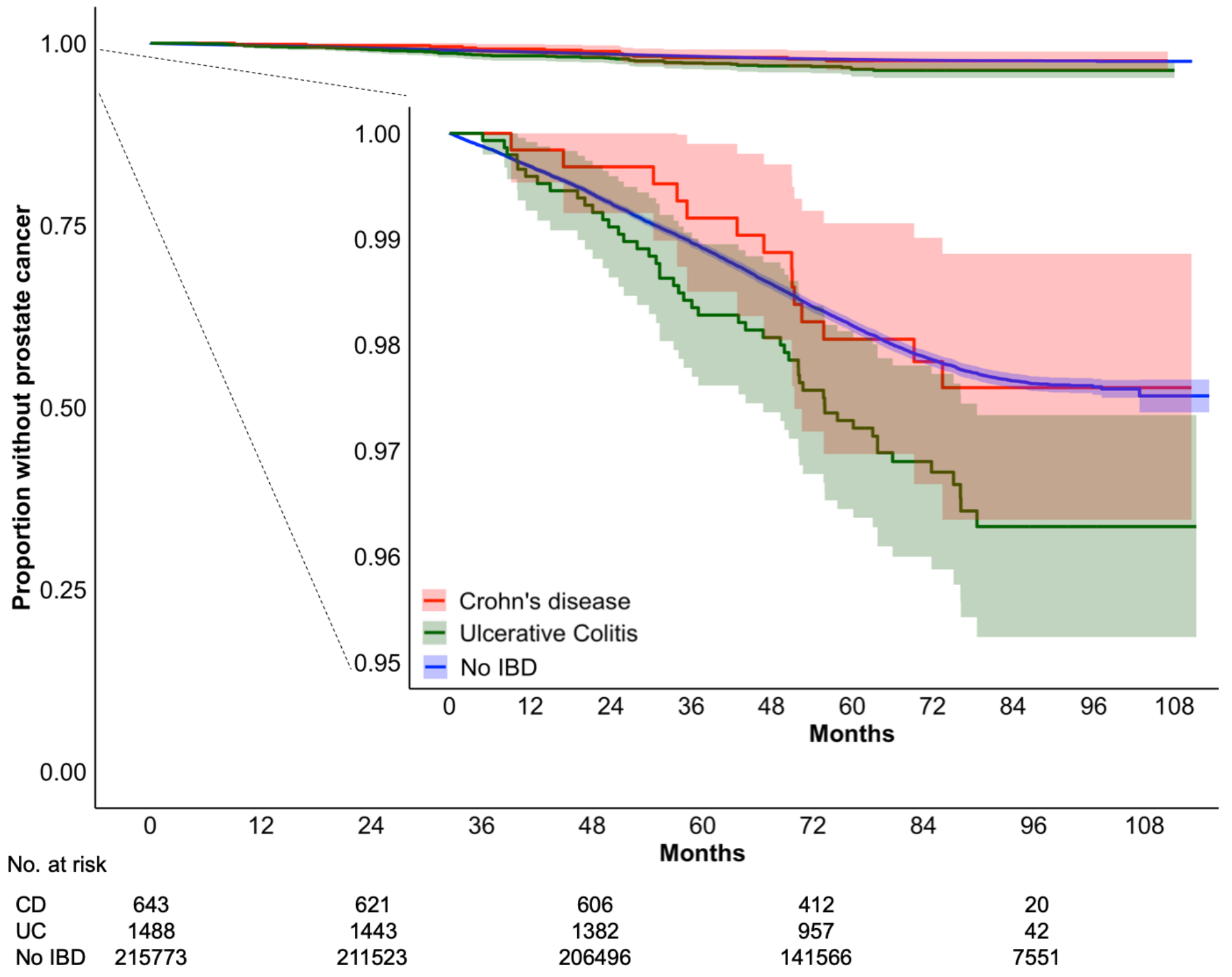


Shading represents $95 \%$ confidence intervals. Log-rank comparing CD to no IBD $p=0.95$ and UC to No IBD $p=0.0023$. Abbreviations: $\mathrm{CD}=$ Crohn's disease; $\mathrm{UC}=$ Ulcerative colitis; IBD = Inflammatory bowel disease 
Table 2. Cox regressions assessing the association between inflammatory bowel disease and future prostate cancer.

\begin{tabular}{ccccccc}
\hline $\begin{array}{c}\text { IBD } \\
\text { status }\end{array}$ & $\mathbf{n}$ & $\begin{array}{c}\text { Person- } \\
\text { years }\end{array}$ & $\begin{array}{c}\text { PC } \\
\text { cases }\end{array}$ & $\begin{array}{c}\text { Incidence/ } \\
\mathbf{1 0 0 , 0 0 0} \\
\mathbf{P Y s}\end{array}$ & $\begin{array}{c}\text { Adjusted } \\
\text { hazard ratio (95\% } \\
\text { Cl) }\end{array}$ & P \\
\hline No IBD & 215,773 & $1,365,610$ & 4,681 & 343 & Reference & \\
Any IBD & 2,311 & 14,379 & 66 & 459 & $1.31(1.03-1.67)$ & 0.029 \\
UC & 1,488 & 9,201 & 49 & 533 & $1.47(1.11-1.95)$ & 0.0070 \\
CD & 643 & 4,021 & 14 & 348 & $1.06(0.63-1.80)$ & 0.82 \\
\hline
\end{tabular}

1. Three separate models were tested: Any IBD vs. No IBD; UC vs. No IBD; and CD vs. No IBD

2. Models adjusted for age at assessment, ethnic group, UK region, smoking status, alcohol drinking frequency, body mass index, Townsend Deprivation Index, family history of prostate cancer, and ever had a PSA test.

Abbreviations: IBD = Inflammatory bowel disease; $U C=$ Ulcerative colitis; $C D=$ Crohn's disease; $\mathrm{PC}=$ Prostate cancer $; \mathrm{Cl}=$ Confidence interval; $\mathrm{PYs}=$ Person-years 
Table 3. Adjusted hazard ratios and $95 \%$ Cls of IBD duration (diagnosis until assessment) and future PC, compared to never having IBD

\begin{tabular}{|c|c|c|c|c|c|c|c|c|c|}
\hline \multirow[b]{2}{*}{$\begin{array}{c}\text { IBD } \\
\text { Status }^{1}\end{array}$} & \multicolumn{4}{|c|}{$<=20$ years } & \multicolumn{4}{|c|}{$>20$ years } & \multirow[b]{2}{*}{$\begin{array}{l}P \text { for } \\
\text { trend }\end{array}$} \\
\hline & $\bar{n}$ & $\begin{array}{c}\text { Person- } \\
\text { Years }\end{array}$ & $\begin{array}{c}\text { PC } \\
\text { Cases }\end{array}$ & $\begin{array}{l}\text { HR }(95 \% \\
\text { CI) })^{2}\end{array}$ & $\mathbf{n}$ & $\begin{array}{l}\text { Person- } \\
\text { Years }\end{array}$ & $\begin{array}{c}\text { PC } \\
\text { Cases }\end{array}$ & $\begin{array}{l}\text { HR }(95 \% \\
\mathrm{Cl})^{2}\end{array}$ & \\
\hline Any IBD & 1,601 & 9,990 & 40 & $\begin{array}{c}1.22 \\
(0.89,1.66) \\
p=0.22\end{array}$ & 710 & 4,389 & 26 & $\begin{array}{c}1.49 \\
(1.01,2.19) \\
p=0.042\end{array}$ & 0.018 \\
\hline UC & 1,076 & 6,679 & 29 & $\begin{array}{c}1.29 \\
(0.89,1.85) \\
p=0.18\end{array}$ & 412 & 2,521 & 20 & $\begin{array}{c}1.87 \\
(1.21,2.91) \\
p=0.0052\end{array}$ & 0.0022 \\
\hline$C D$ & 406 & 2,545 & 9 & $\begin{array}{c}1.11 \\
(0.58,2.14) \\
p=0.75\end{array}$ & 237 & 1,476 & 5 & $\begin{array}{c}0.98 \\
(0.41,2.37) \\
p=0.97\end{array}$ & 0.89 \\
\hline
\end{tabular}

1. Three separate models were tested: Any IBD vs. No IBD; UC vs. No IBD; and CD vs. No IBD; No IBD: N= 215,773; 1.37 million person-years of follow-up; 4,681 PC cases

2. Models adjusted for age at assessment, ethnic group, UK region, smoking status, alcohol drinking frequency, body mass index, Townsend Deprivation Index, family history of prostate cancer, and ever had a PSA test

Abbreviations: IBD = Inflammatory bowel disease; UC = Ulcerative colitis; CD = Crohn's disease; PC = Prostate cancer; $\mathrm{Cl}=$ Confidence interval 